\title{
THE USE OF PHEROMONE TRAPS FOR LEAFROLLER ACTION THRESHOLDS IN PIPFRUIT
}

\author{
S.J. BRADLEY ${ }^{1}$, J.T.S. WALKER ${ }^{1}$, C.H. WEARING ${ }^{2}$, \\ P.W. SHAW ${ }^{3}$ and A.J. HODSON ${ }^{4}$
}

\author{
The Horticulture and Food Research Institute of New Zealand Ltd \\ ${ }^{1}$ Hawkes Bay Research Centre, Private Bag 1401, Havelock North \\ ${ }^{2}$ Clyde Research Centre, RDI Alexandra \\ ${ }^{3}$ Nelson Research Centre, P.O. Box 220, Motueka \\ ${ }^{4}$ Taylor Pinchin and Associates, P.O. Box 56 Hastings
}

\begin{abstract}
In orchards using New Zealand Integrated Fruit Production for pipfruit (NZIFP-P), the decision to treat for leafroller (Lepidoptera: Tortricidae) results from sampling of 200 fruit clusters or 200 shoots. This required a large time commitment by the grower, was subject to misidentification and was a poor predictor of damage at harvest. In 1996-97, cumulative trap catch of Epiphyas postvittana (LBAM) within NZIFP-P research plots was found to be highly correlated with damage at harvest and a cumulative catch of 30 moths after 15 December was established as a tentative threshold. Insecticides were to be applied at least 21 days apart during periods of high trap catches. In 1997-98, this threshold was successfully used by 300 growers and using their trap data, the effect of increasing the threshold to 50 was examined. The 50 moth threshold is not appropriate in Otago, but in northern regions shows some potential and requires further evaluation.
\end{abstract}

Keywords: Lightbrown apple moth, leafroller, pheromone traps, thresholds, Integrated fruit production.

\section{INTRODUCTION}

Leafrollers (Lepidoptera: Tortricidae), are key pests of apple in New Zealand. Calendar-based programmes rely on fortnightly applications of organophosphate insecticides to control leafrollers, while integrated programmes such as the New Zealand Integrated Fruit Production - Pipfruit (NZIFP-P; Batchelor et al. 1997) use sprays of insect growth regulators (IGR) based on leafroller phenology and action thresholds.

In the pilot NZIFP-P programme, leafroller sprays were applied at the beginning of the spring generation and thereafter when a larva or fresh damage was found on a sample of 200 shoots (until 31 December) or 200 fruit clusters (after 1 January) (Walker et al. 1997). Samples were taken monthly and typically took the grower or pest scout over one hour per sample per cultivar ha to complete (H. Stiefel pers. comm.). Insect growth regulators are the main insecticides used in NZIFP-P. Adult insects are not killed by these products and this may enable the monitoring of adult moths, rather than larvae, to assess the risk of leafroller damage.

Pheromone traps have been used for leafroller monitoring by some growers since the late 1980s (Shaw et al. 1993). They have been used to assess species composition in the orchard, but have also permitted removal of up to two spray applications from calendar-based programmes (Shaw et al. 1993). Pheromone traps have never been considered as adequate predictors of crop damage due to leafrollers' wide host range and the high populations surrounding orchards, (Tomkins et al. 1987; Suckling and Burnip 1993). However, Tomkins et al. (1987) did find a relationship between pheromone trap catches in apple orchards and the numbers of gravid females caught in port wine traps; this suggests that pheromone trap catches could predict the risk of leafroller damage.

Proc. 51st N.Z. Plant Protection Conf. 1998: 173-178 
This paper describes the development of action thresholds for leafrollers in apple orchards based on the numbers of male moths caught in pheromone traps.

\section{MATERIALS AND METHODS}

In 1996-97, the HortResearch IFP research block at Lawn Rd, Hastings (comprising of cv. 'Gala', 'Braeburn' and 'Fuji'), was divided up for sampling into 12 plots of approximately 0.13 ha. The HortResearch Biological Fruit Production (BFP) block at Crosses Rd, Havelock North was similarly divided into 0.18 ha plots of each of the above cultivars. The HortResearch IFP research block at Appleby, Nelson has 'Sturmer' and 'Granny Smith', and was sampled in four 0.15 ha plots. Two hundred shoots and 200 fruit clusters were examined for the presence of leafroller each month from November to harvest. A Delta type pheromone trap (Suckling and Shaw 1992) baited with pheromone for Epiphyas postvittana (LBAM) was placed in the centre of each plot and recorded weekly. Sticky bases and pheromone lures were replaced at three- and six-weekly intervals respectively.

In the 1997/98 season, growers used NZIFP-P operated LBAM pheromone traps on a similar basis, but at a rate of one trap per 2 ha of orchard (Anon. 1997). In Otago, where Planotortrix octo is another key leafroller species, P. octo traps were also operated and trap catches of the two species added together. Trap catches from 5 - 87 commercial NZIFP-P orchards were used to get a mean trap catch for each region. These mean regional trap catches were used to examine differences in theoretical spray programmes when using a 30 or 50 moth action threshold.

At harvest, 2000 randomly picked fruit were assessed for leafroller damage from each plot on the research orchards. Two thousand fruit were assessed from harvested bins of fruit on commercial orchards and results are reported in Walker et al. 1998.

\section{RESULTS AND DISCUSSION}

The relationships between monitoring and damage at harvest are presented in Figure 1. Despite the higher incidence of damage on shoots, there was a poor relationship ( $\mathrm{R}^{2}=0.056$, n.s.) between the percentage of damaged shoots and harvested fruit (Figure 1a). As expected, there was a significant correlation $(\mathrm{P}<0.001$, $\mathrm{df}=17$ ) between the percentage of damaged fruit clusters monitored after December, and the percent of fruit damaged when harvested between February and April (Figure 1b). The principal cause for concern was that on average $0.5 \%$ (and up to $2 \%$ ) fruit damage remained undetected with monthly samples of 200 clusters (Figure 1b). This was a greater problem with short stemmed varieties that were difficult to examine without picking the fruit. The number of LBAM caught in pheromone traps between mid December and harvest in IFP plots, had a significant correlation with fruit damage $(\mathrm{P}<0.001, \mathrm{df}=14$, Figure 1c). Later harvested cultivars were generally exposed to more moths and had greater damage. Nelson plots had higher leafroller catches and subsequently had higher levels of damage, despite increased insecticide applications. Blocks that had less than 50 moths caught between 15 December and two weeks prior to harvest, generally had less than $0.5 \%$ fruit damage.

We were able to demonstrate a relationship between trap catch and damage at harvest for two reasons; traps were placed internally in the blocks and the insecticides used were selective. Previous New Zealand studies conducted under organophosphate spray programmes (Suckling and Burnip 1993; Shaw et al. 1993; Wearing 1995), have relied on traps located on the orchard boundary which trapped moths originating from unsprayed areas. Similar studies in Washington State have found internal trapping with pheromone lures with a tenth of the standard dose to be a better indicator of leafroller damage in orchards than the normal boundary pheromone trapping (Alway 1997; 1998). The selectivity of the IGR insecticides, which only kill larvae, enabled adult moths to survive within our sprayed plots. In earlier studies (Suckling and Burnip 1993; Shaw et al. 1993; Wearing 1995), adults present within the blocks often would have been killed by the regular organophosphate insecticide applications and this weakened the relationship between trap catches and potential damage. 

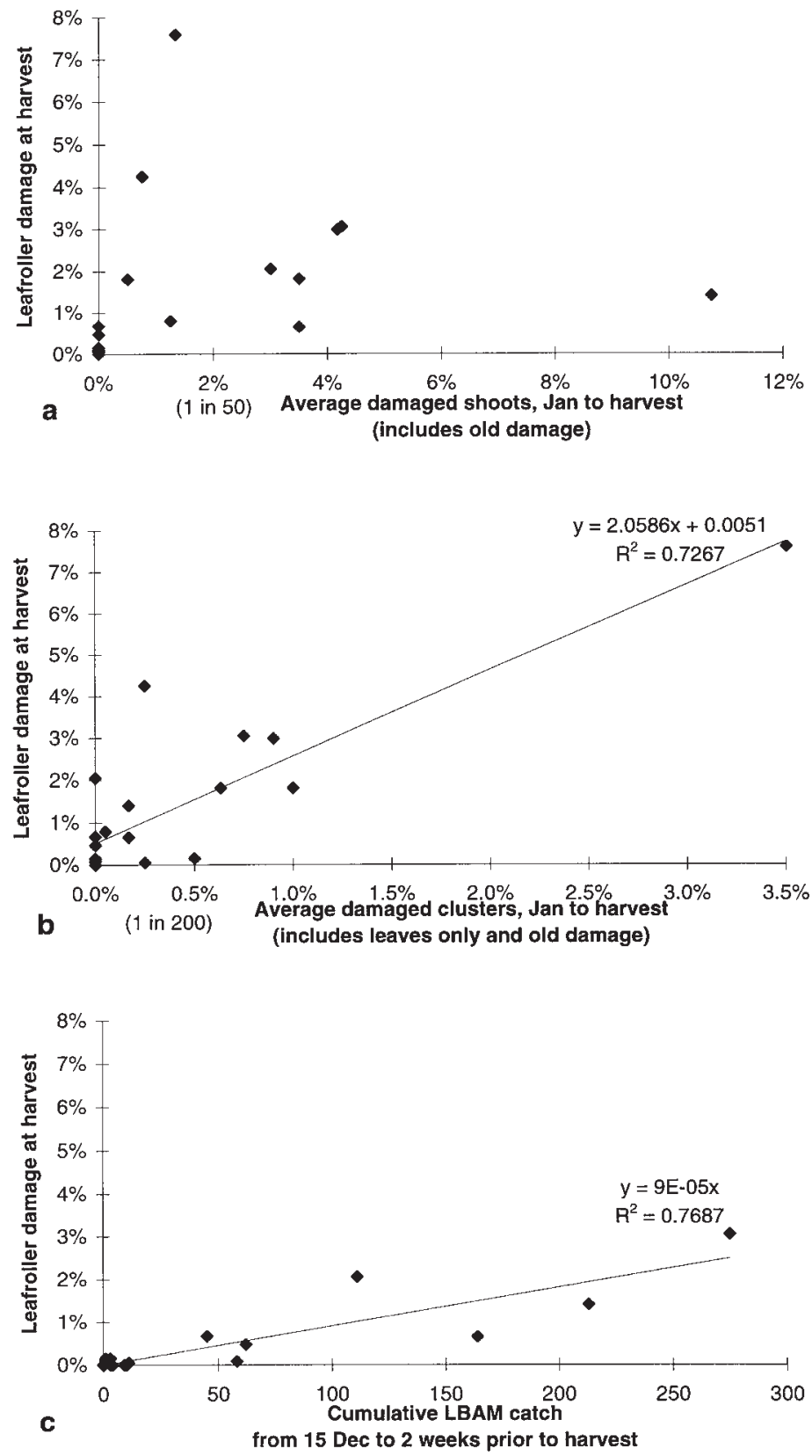

FIGURE 1: The relationship between leafroller damage at harvest and (a) average damaged shoots, (b) average damage clusters, or (c) cumulative LBAM trap catch. 
The plots in which a cumulative total of less than 50 LBAM were caught, had no post-December insecticides applied and resulted in less than $0.5 \%$ damage (which was within acceptable limits). This indicated a possible threshold for spray application viz. an accumulated catch of 50 male moths. To be conservative, the slope of the upper $95 \%$ confidence interval was used to predict that 30 LBAM could result in $0.5 \%$ damage. Due to the small plot size of these trials, it is likely that traps would be interfering with each other and catching fewer moths than traps spaced at greater intervals, such as those on commercial orchards. This added a further level of conservatism into the 30 moth threshold.

In the NZIFP-P programme, the time and cost involved in leafroller monitoring by searching fruit and foliage was seen as a major barrier to the uptake of the programme. To address this concern, the recommended leafroller control programme during the 1997/98 season (Anon. 1997), was:

1. An application of tebufenozide or lufenuron at the beginning of the spring generation of leafrollers (petal-fall (early November) in North Island, Nelson and Marlborough orchards (northern regions), or December in Canterbury and Otago orchards).

2. In the northern regions, an application of tebufenozide or lufenuron, in late November or early December when leafroller damage was found in a 50 shoot, and 1000 fruit sample (this sample was required for blackspot monitoring).

3. From mid December, a cumulative trap catch of 30 LBAM (or LBAM + P. octo in Otago) in an internal trap was used as a basis for IGR treatment, with sprays to be applied no closer than 21 days. In the northern regions, an application of tebufenozide was recommended 14 days prior to harvest to protect the crop from leafroller damage over the harvest period.

Codling moth (Cydia pomonella) activity could also invoke the use of one of the above insecticides (Wearing and Charles 1978), and in most districts this was mainly during December and January. Organophosphate sprays may have been substituted for the IGR where mealybug, woolly apple aphid or scale insects were a problem.

In Otago, the relationship between $P$. octo trap catch and damage at harvest has not been established for orchards using NZIFP-P. While there may be differences in trapping efficiency between LBAM and P. octo (Suckling et al. 1994), a simple additive method was used by growers who would have been at risk of fruit damage if $P$. octo was ignored. It is possible that in future, insecticide use and timing may be based on a day-degree model in this district (Wearing 1995).

Walker et al. (1998) described average insecticide use on Braeburn during the 1996/97 and 1997/98 seasons on NZIFP-P orchards in Hawkes Bay, Nelson and Otago. As previously stated, during 1996/97 the threshold was based on foliage and fruit sampling. In Hawkes Bay, an average of 2.6 post-bloom IGR insecticides was applied during 1996/97, resulting in $0.3 \%$ leafroller damage at harvest. In 1997/98, post-bloom IGR use increased to 3.1 applications and leafroller damage decreased to $0.2 \%$. IGR use in Nelson decreased between the two seasons (3.3 and 2.9 applications respectively), and leafroller damage also decreased from $1.9 \%$ to $0.7 \%$. The improvement in leafroller control in Nelson is in some part due to growers using the correct rate of tebufenozide in the 1997/98 season (P. Shaw, unpubl. data). There was a slight decrease in IGR use in Otago, from an average of 2.9 applications to 2.7. Damage at harvest remained unchanged with $0.2 \%$ damage in both seasons. Gisborne and Waikato in the 1997/98 season, applied on average one more IGR application (4.0 and 4.4 respectively), than other regions. This increase is attributed to a higher proportion of orchards treating for codling moth in November and December and exceeding the recommended maximum of five applications. Leafroller damage at harvest in these regions averaged less than one apple per 2000 fruit sample.

Table 1 shows the seasonal average LBAM $( \pm$ P. octo) catches for each district derived from commercial NZIFP-P orchards. The highest leafroller trap catches were in Gisborne and the lowest trap catches were experienced in Central Otago, despite these being the sum of both LBAM and $P$. octo trapping. Between 100-200 moths were caught in other districts. Using the 30 moth threshold, the action threshold was usually 
exceeded in mid-January and then again at the 21 day minimum interval. When the threshold was increased to 50 moths, the first spray was delayed by 1-2 weeks, which meant one less insecticide could be used (if the 21 day minimum interval was observed), in all districts except Nelson and Wairarapa (Table 1). Catches in Gisborne orchards exceeded 30 moths within two weeks of trapping and then required a regular 21 day spray programme throughout the season. If the threshold was increased to 50 moths, spray timing would still protect the fruit, yet insecticide use would be decreased in a region with high IGR use in the previous season (Walker et al. 1998). Increasing the threshold to 50 in Otago, delayed the first threshold violation by three weeks, to early/mid February, when there is a lower proportion of early instar larvae between generations and the spray timing would be poor (Wearing 1995).

\section{TABLE 1: Theoretical spray programmes for Braeburn apples in six districts based on a threshold of 30 or $50 \mathrm{LBAM}$ moths in pheromone traps between 15 Dec 97 and 2 Mar 98.}

\begin{tabular}{|c|c|c|c|c|c|c|}
\hline \multirow[b]{2}{*}{ Region } & \multirow[b]{2}{*}{$\mathrm{n}$} & \multirow[b]{2}{*}{$\begin{array}{l}\text { Cum. } \\
\text { trap } \\
\text { catch }\end{array}$} & \multicolumn{2}{|c|}{30 moth threshold } & \multicolumn{2}{|c|}{50 moth threshold } \\
\hline & & & $\begin{array}{l}\text { Date of } \\
\text { first } \\
\text { threshold } \\
\text { violation }\end{array}$ & $\begin{array}{l}\text { No. of } \\
\text { sprays from } \\
\text { Dec } 15 \text { to } \\
\text { Mar } 2\end{array}$ & $\begin{array}{l}\text { Date of } \\
\text { first } \\
\text { threshold } \\
\text { violation }\end{array}$ & $\begin{array}{l}\text { No. of } \\
\text { sprays from } \\
\text { Dec } 15 \text { to } \\
\text { Mar } 2\end{array}$ \\
\hline Gisborne & 15 & 232 & $29 \mathrm{Dec}$ & 4 & 5 Jan & 3 \\
\hline Waikato & 25 & 136 & $12 \mathrm{Jan}$ & 3 & 19 Jan & 2 \\
\hline Hawkes Bay & 87 & 114 & 19 Jan & 3 & $26 \mathrm{Jan}$ & 2 \\
\hline Wairarapa & 18 & 180 & 5 Jan & 3 & $19 \mathrm{Jan}$ & 3 \\
\hline Nelson & 49 & 190 & 19 Jan & 3 & $26 \mathrm{Jan}$ & 3 \\
\hline Central Otago & 5 & $82^{1}$ & 19 Jan & 2 & $9 \mathrm{Feb}$ & 1 \\
\hline
\end{tabular}

${ }^{1}$ Central Otago uses a cumulative total of both LBAM and Planotortrix octo catches.

In the Gisborne, Waikato, Hawkes Bay, Wairarapa, and Nelson districts, the 1-2 week delay in the first threshold violation by using a 50 moth threshold would probably have little effect on fruit damage at harvest on most orchards. As the model is based on average regional catches and does not take account of site to site variation in the relationship between catch and damage, any move to raise the threshold should be evaluated on individual blocks on a range of grower orchards.

These thresholds were derived from and are only valid for orchards which start the season with an IGR with a long residual life. The slope of the regression between leafroller trap catches and fruit damage in untreated orchards is significantly steeper than those using IGRs, and using the thresholds from mid December onwards in previously unsprayed blocks resulted in significantly higher damage levels (Bradley and Shaw unpubl. data).

\section{CONCLUSION}

Using pheromone trap catches as action thresholds instead of foliage and fruit sampling was considerably more convenient and slightly reduced the leafroller monitoring costs for growers using NZIFP-P, without greatly changing their insecticide use or their risk of crop damage. Analysis of average trap and damage data based on the 30 moth threshold, indicates that a higher threshold of 50 moths may be satisfactory in northern regions, but as analyses were based on average catches, further research is needed on individual orchards before an increase in the threshold is recommended.

\section{ACKNOWLEDGEMENTS}

This research was supported by the Foundation for Research, Science and Technology and ENZAFRUIT New Zealand. The authors wish to thank Amanda Ryan (ENZA), Vanessa Murrell, Roger Wallis, Peter Lo, Lyn Cole (HortResearch) and the many growers and consultants who provided and collected data. 


\section{REFERENCES}

Alway, T., 1997. Monitoring leafrollers with pheromone traps. Washington State University Areawide IPM Update Vol. 2, No. 1.

Alway, T., 1998. Monitoring leafrollers with pheromone traps. Washington State University Areawide IPM Update Vol. 3, No. 4.

Anon., 1997. New Zealand Integrated Fruit Production - Pipfruit Manual. ENZA New Zealand (International), Hastings.

Batchelor, T.A., Walker, J.T.S., Manktelow, D.W.L., Park, N.M. and Johnson, S.R., 1997. New Zealand integrated fruit production for pipfruit - charting a new course. Proc. 50th N.Z. Plant Prot. Conf.: 258-263.

Shaw P.W., Cruikshank, V.M. and Suckling D.M., 1993. Commercial use of pheromone traps in Nelson. Proc. 46th N. Z. Plant Prot. Conf.: 135-140.

Suckling, D.M., Brunner, J.F., Burnip, G.M. and Walker, J.T.S., 1994. Dispersal of Epiphyas postvitana (Walker) and Planotortrix octo (Dugdale)(Lepidoptera: Tortricidae) at a Canterbury, New Zealand orchard. N. Z. J. Crop and Hort. Sci. 22: $225-234$.

Suckling, D.M. and Burnip, G.M., 1993. Pheromone trapping and insecticide use in Canterbury apple orchards. Proc. 46th N.Z. Plant Prot. Conf.: 129-134.

Suckling, D.M. and Shaw, P.W., 1992. Conditions that favour mating disruption of Epiphyas postvittana (Lepidoptera: Tortricidae). Environ. Entomol. 21(5): 949956.

Tomkins, A.R., Penman, D.R. and Chapman, R.B., 1987. Use of traps for monitoring adult leafrollers in apple orchards. N. Z. J. Exp. Agric. 15(1): 91-96.

Walker, J.T.S., Hodson, A.J., Wearing, C.H., Bradley, S.J., Shaw, P.W., Tomkins, A.R., Burnip, G.M., Stiefel, H.E. and Batchelor, T.A., 1997. Integrated fruit production for New Zealand pipfruit: Evaluation of pest management in a pilot programme. Proc. 50th N.Z. Plant Prot. Conf.: 258-263.

Walker, J.T.S., Wearing, C.H., Bradley, S.J., Shaw, P.W., Burnip, G.M., Tomkins, A.R., Richardson, C. and Hodson, A.J., 1998. Integrated Fruit Production (IFP) for New Zealand pipfruit: Evaluation of pest management recommendations. Proc. 51st N.Z. Plant Prot. Conf.: this volume.

Wearing, C.H., 1995. A recommended spray programme for leafroller and codling moth control in Central Otago apple orchards. Proc. 48th N.Z. Plant Prot. Conf:: 111-116.

Wearing, C.H. and Charles, J.G., 1978. Integrated control of apple pests in New Zealand 14. Sex pheromone traps to determine applications of azinphos-methyl for codling moth control. Proc. 31st Weed and Pest Control Conf.: 229-235. 